\title{
DECISION SUPPORT FOR REVERSE LOGISTICS USING NEURAL NETWORKS
}

\author{
Magdalena Scherer \\ Department of Engineering Management, Czestochowa University of Technology \\ Czestochowa, Poland \\ mscherer@zim.pcz.pl
}

\begin{abstract}
Reverse logistics can reduce production costs by re-inclusion of waste in the production chain, which, after proper processing, can be raw materials, semi-finished products or products. Proper reverse logistics management improves the efficiency of waste material flows in the manufacturing company. Computational intelligence tools can be a good tool for managing reverse logistics in a company. In the paper, we use artificial neural networks to predict waste production volume on the basis of the previous months. We trained the network with waste data from a real production company. We obtained satisfactory prediction accuracy.
\end{abstract}

Keywords: neural networks, sales forecasting, machine learning

\section{Introduction}

Proper business management is usually based on an analysis of both the enterprise and its surroundings. In addition to the current information, information about future events in the company and its environment is extremely important. Decisions can be more accurate if they are made on the basis of reliable predictions. Forecast demand in the enterprise is due to uncertainty related to the future as well as delays in time since the decision was taken as a result of its consequences. Forecasts are used in many areas of the company, among others, in sales, production, human resources, inventory, finance, or logistics. Accurate forecasts are also needed for reverse logistics activities.

As statistics show, most waste is generated in the production process [1]. Industrial waste in Poland is the largest proportion of all waste. Waste generated from the production activity is therefore the main object of reverse logistics due to the scale of occurrence and the degree of risk to the environment. Reverse logistics is designed to incorporate waste after proper recycling into the logistic chain as raw materials or semi-finished products. Reverse logistics models waste streams and related information from their origin to their place of management, involving the recovery of value (through re-use, recycling or reclaiming) or to the proper disposal or long-term storage to economize operation and to protect the environment [2]. Waste management is not only a civic obligation but also a practice and commitment to the current waste management [3]. 
One of the ways to increase company performance and competitiveness is to reduce production costs or total cost [4]. One of the tasks of reverse logistics is to reduce production costs by re-inclusion of waste in the production chain, which, after proper processing, can be raw materials, semi-finished products or products. Proper reverse logistics management improves the efficiency of waste material flows in the manufacturing company. Enterprises increasingly focus their attention on environmental actions by adopting an environmental goal not only to minimize the amount of waste generated, but above all the opportunity to bring as much waste into the economic cycle as possible. Quantitative assumptions for projects, reducing the negative impact of generated waste on the environment can only be fulfilled if it is possible to predict the size of precipitation streams. Various forecasting methods are used to manage reverse logistics. They allow accurate forecasting of waste, which translates into quantifiable planning of return flows. In the paper we use artificial neural networks to train them from past data to predict monthly waste production. The paper is organized as follows. In the next section, we provide a brief introduction to neural networks. Section 3 describes the data collected in the examined company and their analysis. Experiments performed on real data are presented in Section 4.

\section{Neural networks}

Neural networks can be divided in terms of their distinguishing characteristics, i.e. the type of input signal, the network architecture or the way they are taught. The input signal can be a binary signal (Hopfield network, Hamming network, ART 1) or a continuous signal (perceptron, Kohonen network) [5].

Considering the structure of the network, there are three basic types: unidirectional networks, recursive networks, and cellular networks. In unidirectional networks, neuronal connections are carried out from the neuron of the lower layer to the neuron of the higher layer. The first layer is the input layer and the last one is the output layer. There are no links between the neurons within the same layer or the connections from the upper layer to the lower layer. An example of this type of network is the perceptron. In recurrent networks, there are two-way links between neurons of different layers. Connections in the return direction can provide feedback. There are connections between neighbouring neurons in the cellular network.

Neural networks also distinguish the type of training. Networking can be done under supervision (teaching with a teacher) or without supervision (teaching without a teacher). Networking is about enforcing a specific neural network response to the input signals. Therefore, the choice of teaching method is very important. Supervised teaching is based on the appropriate weight selection, so that the output signals are as close as possible to the desired values. The set of learning data includes both input signal groups and responses to these signals. On the other hand, unattended learning is based on independent analysis of the dependence in the test set by the neural network. During learning, the network receives no information 
about the desired response. Training data contain only a set of input signals. Networks with such action are called self-organizing or self-associative [6].

The most commonly used neural architecture in both research and commercial models are perceptron networks. These are unidirectional networks, where neurons are grouped in at least two layers. There may be one or more hidden layers between these layers. The signals are passed from the input layer to the output layer, without feedback to the previous layers [7]. The perceptron network was used in experiments in this article. We used a network with one hidden layer with ten neurons and one output neuron, presented in Figure 1.

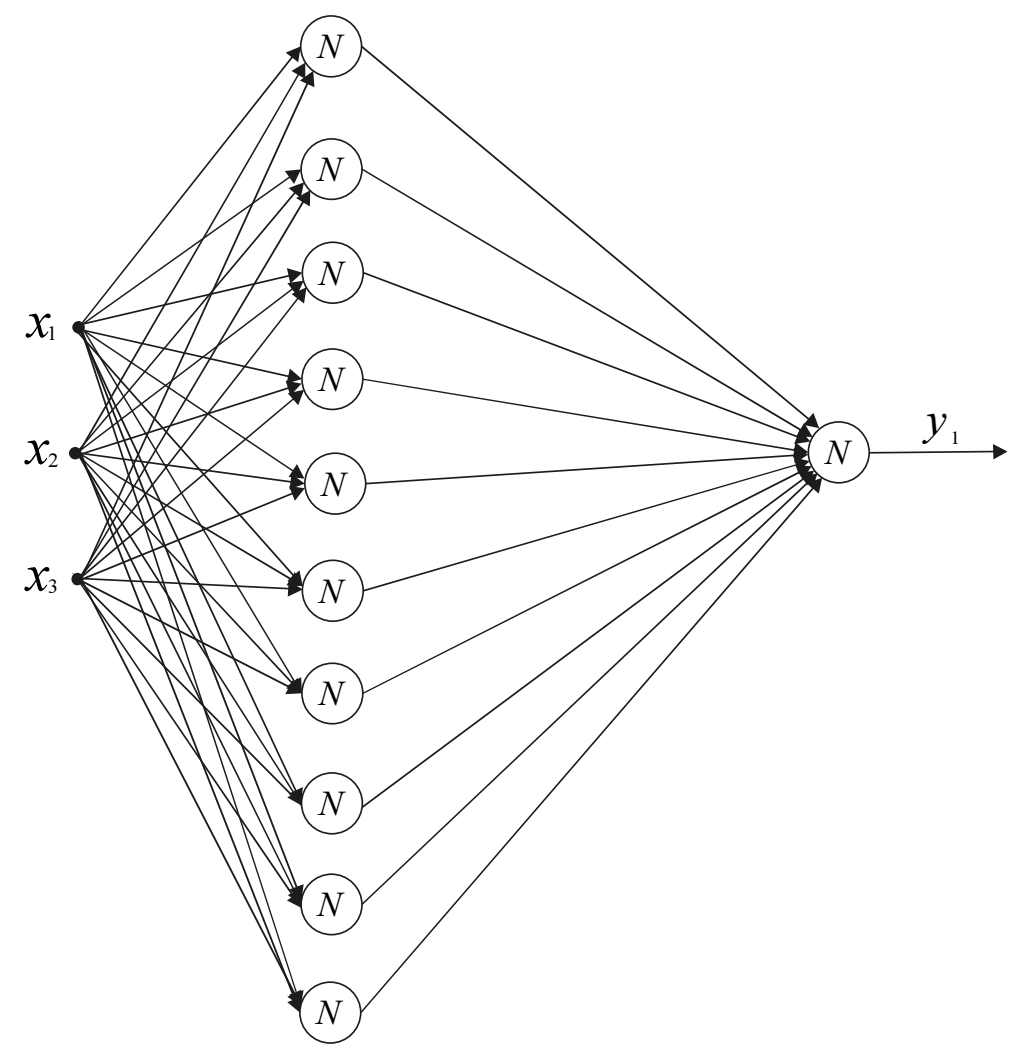

Fig. 1. Feedforward artificial neural network used in the experiments

Layers in feedforward neural networks consist of neurons [8]. The operation of the neuron can be described using the formula

$$
y=f\left(\sum_{i=0}^{n} x_{i} w_{i}\right),
$$

where $n$ is the number of inputs to the neuron, $x_{1}, \ldots, x_{n}$ are input signals, $w_{0}, \ldots, w_{n}$ are synaptic weights, $y$ is the output value, $w_{0}$ is bias and $f$ is the activation 
function. Synaptic weights are parameters (real numbers) that are adapted during training from data. The input signals $x_{0}, \ldots, x_{n}$ are multiplied by the corresponding weights $w_{0}, \ldots, w_{n}$. The resulting values are summed and then subjected to an activation function that is usually nonlinear to enable the existence of more than one layer. Then we can describe a multilayer neural network by the following formulas. The output of the $i$-th neuron in step $t$ of the training algorithm is

$$
y_{i}^{(k)}(t)=f\left(s_{i}^{(k)}(t)\right), \quad s_{i}^{(k)}(t)=\sum_{j=0}^{N_{k-1}} w_{i j}^{(k)}(t) x_{j}^{(k)}(t) .
$$

The error on the $i$ th output of the $k$-th layer is defined by

$$
Q_{i}^{(k)}(t)=\left\{\begin{array}{ll}
d_{i}^{(L)}(t)-y_{i}^{(L)}(t) & \text { for } k=L \\
\sum_{m=1}^{N_{k+1}} \delta_{m}^{(k+1)}(t) w_{m i}^{(k+1)}(t) & \text { for } \quad k=1, \ldots, L-1
\end{array},\right.
$$

where

$$
\delta_{i}^{(k)}(t)=\varepsilon_{i}^{(k)}(t) f^{\prime}\left(s_{i}^{(k)}(t)\right) .
$$

The error is defined between neuron output and the desired (training) value from the training dataset. And finally the network weights are modified in each step $t$ by

$$
w_{i j}^{(k)}(t+1)=w_{i j}^{(k)}(t)+2 \eta \delta_{i}^{(k)}(t) x_{j}^{(k)}(t),
$$

where $\eta$ is a learning coefficient set in advance. Formulas (2)-(5) define the backpropagation algorithm used to adapt the network weights to the dataset in an iterative process. Weights are initialized randomly as there exists no simple way to choose optimal weight values at the beginning of the training process.

Neural networks are used to solve various problems [9-12]. However, every problem requires a proper network design and adaptation. The appropriate network topology, the number of neurons in layers and sometimes the number of network layers must be chosen. Next, we need to prepare a training and testing set. The network must be trained and afterwards tested with data not used during training.

\section{Data acquisition and preparation}

The research uses data concerning manufacturing volume from one of the typical manufacturing companies. The waste catalogue according to the Regulation of the Ministry of the Environment of 9 December 2014 on the waste catalogue divides the waste according to the source of their formation into twenty groups. Each type 
of waste is assigned a six-digit code, and in the data used in the paper, there is waste from the following groups: 080111 - Waste paint etc., 150102 - Plastic packaging, 130110 - Mineral hydraulic oils, 150110 - Packaging contaminated by hazardous substances, 150202 - Sorbents, 150203 - Filter materials, wiping cloths, 160213 - Used equipment containing dangerous components. Data were normalised to ease the artificial neural network process.

The nature of the production process in the researched enterprise results in certain dependencies between the generated waste of the groups being distinguished. Indication of the existence of links between different categories is one of the basic objectives of economic research. Correlation is a measure of the relationship between variables, which is determined by the correlation coefficient [13]. The seven selected waste groups were analyzed for correlation to determine to what extent the data are interrelated. For this purpose, the Pearson correlation coefficient was calculated for the respective waste groups. This coefficient has a value in the range $<-1$; 1 $>$, where zero means total absence of correlation, 1 means complete positive correlation, and -1 signifies complete negative correlation. Positive correlation means that the value of the second variable increases with the increase of the first variable. In the case of negative correlation, the increase in the value of the first variable causes the second variable to fall. The Pearson correlation coefficient is expressed by formula:

$$
\bar{y}=\frac{\sum_{i=1}^{n}\left(\bar{x}_{i}-\bar{x}\right)\left(\bar{y}_{i}-\bar{y}\right)}{\sqrt{\sum_{i=1}^{n}\left(x_{i}-\bar{x}\right)^{2}} \sqrt{\sum_{i=1}^{n}\left(\bar{y}_{i}-\bar{y}\right)^{2}}},
$$

where $x_{i}$ is the $i$-th value of variable $x, y_{i}$ unit $i$-th value of variable $y, \bar{x}$ is the arithmetic mean of variable $x, \bar{y}$ the arithmetic mean of variable $y$, and $n$ is the number of observations. The obtained results from the correlation analysis are presented in Table 1. Correlation coefficients indicate that the data are not correlated, thus all waste groups will be predicted separately.

Table 1

Correlation coefficients between individual monthly waste amounts

\begin{tabular}{|c|c|c|c|c|c|c|c|}
\hline Waste & 80111 & 150102 & 130110 & 150110 & 150202 & 150203 & 160213 \\
\hline 80111 & 1.00 & 0.20 & -0.04 & 0.09 & 0.23 & -0.05 & -0.08 \\
\hline 150102 & 0.20 & 1.00 & -0.03 & 0.03 & -0.01 & -0.04 & -0.04 \\
\hline 130110 & -0.04 & -0.03 & 1.00 & 0.02 & -0.01 & -0.04 & 0.07 \\
\hline 150110 & 0.09 & 0.03 & 0.02 & 1.00 & 0.17 & -0.13 & 0.02 \\
\hline 150202 & 0.23 & -0.01 & -0.01 & 0.17 & 1.00 & -0.06 & 0.06 \\
\hline 150203 & -0.05 & -0.04 & -0.04 & -0.13 & -0.06 & 1.00 & -0.04 \\
\hline 160213 & -0.08 & -0.04 & 0.07 & 0.02 & 0.06 & -0.04 & 1.00 \\
\hline
\end{tabular}


Figure 2 shows the annual production for all the collected groups of waste.

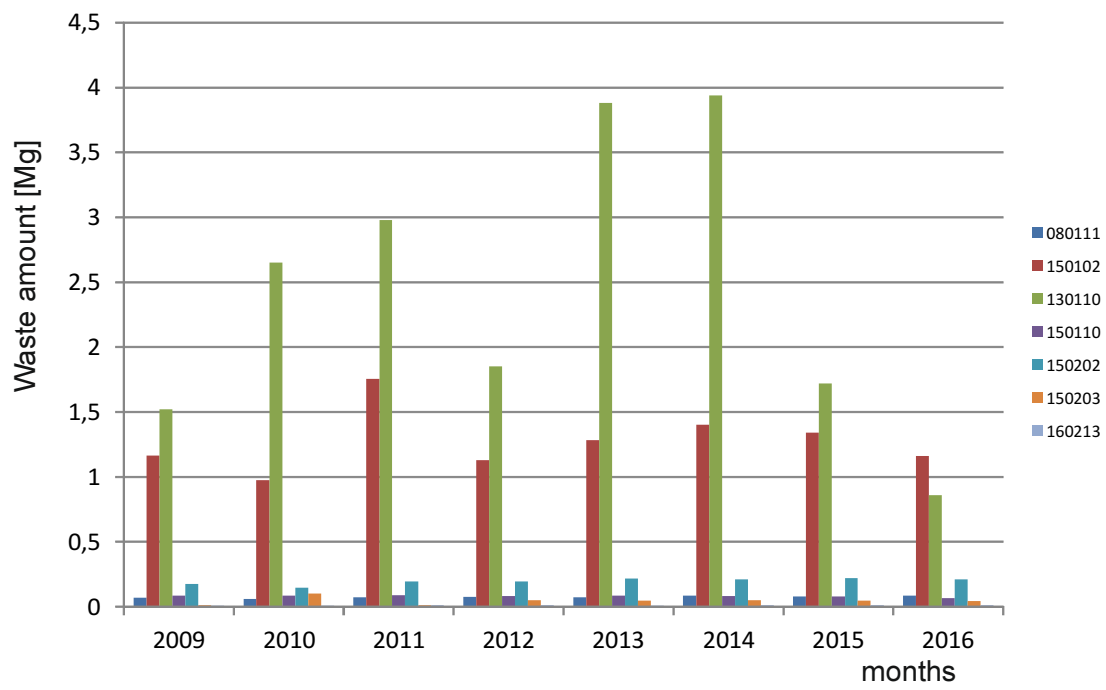

Fig. 2. Annual amounts of individual waste in the years 2009-2016 in the examined enterprise

\section{Experiments}

We used the multilayer nonlinear perceptron neural network to predict waste production in the next month on the basis of the previous three months. The data are described in Section 3. We created our neural network in the Matlab Neural Network Toolbox with net $=$ feedforwardnet $(10)$ command.

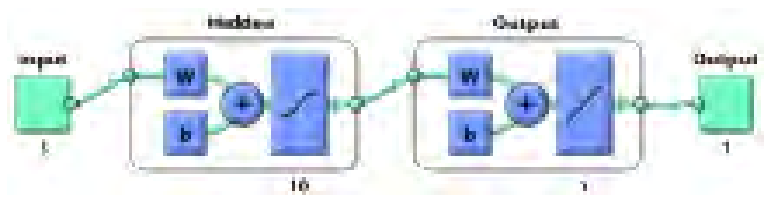

Fig. 3. Neural network defined in Matlab Neural Network Toolbox

The training process took 100 epochs, i.e. full presentations of the training dataset and the error during training process is shown in Figure 4.

After the training was complete we computed prediction and checked the trained network output against the data. The results of the obtained accuracy for each type of waste are presented in Table 2 .

An exemplary plot of the trained neural network output for waste number 80111 against real data is presented in Figure 5. 


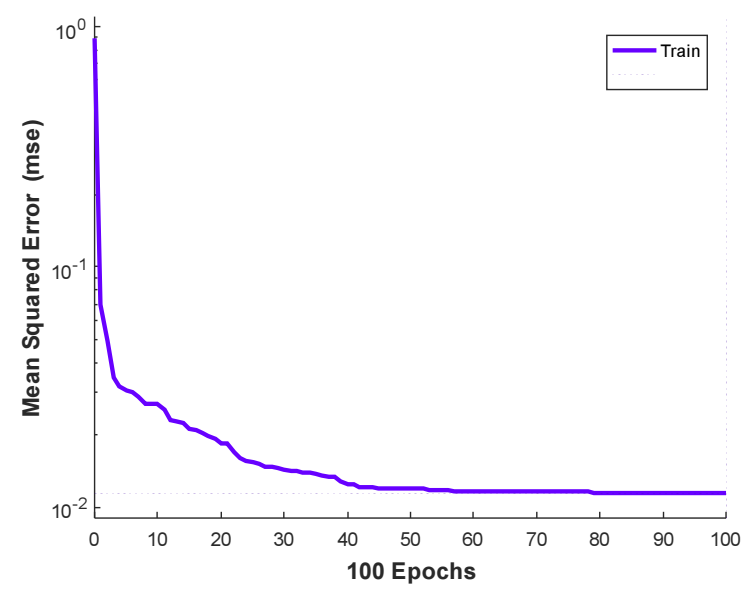

Fig. 4. Error during training for 80111 waste

Table 2

Monthly waste amount prediction root mean square (RMSE) errors

\begin{tabular}{|c|c|}
\hline Waste & RMSE \\
\hline 80111 & 0.1068 \\
\hline 150102 & 0.1012 \\
\hline 130110 & 0.1190 \\
\hline 150110 & 0.1899 \\
\hline 150202 & 0.2011 \\
\hline 150203 & 0.1298 \\
\hline 160213 & 0.1920 \\
\hline
\end{tabular}

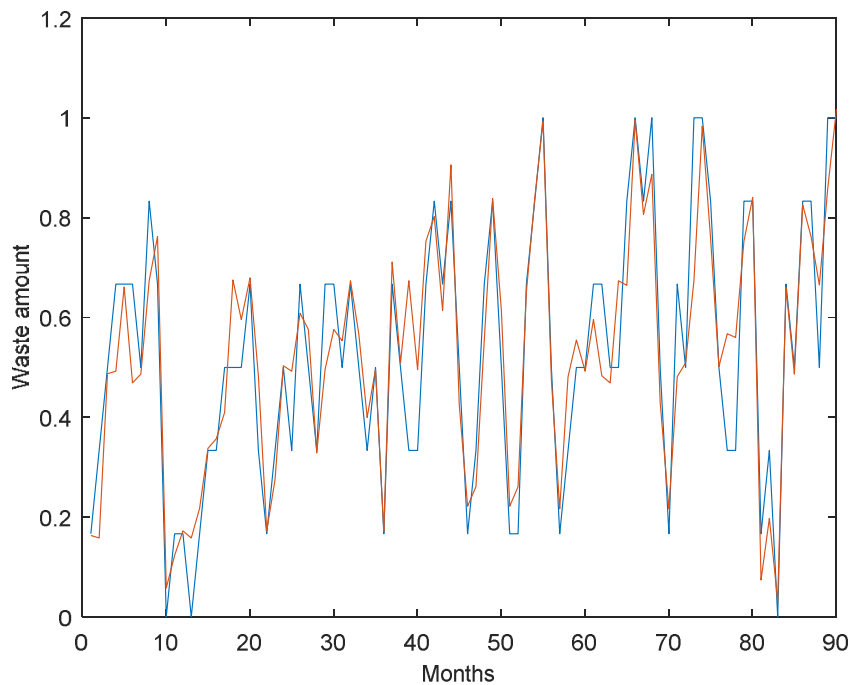

Fig. 5. Exemplary plot of the trained neural network output for waste number 80111 against real data 
We can observe that the predicted waste volume is very similar to the real one, thus the presented neural network can be a useful tool in making decisions concerning waste management in companies.

\section{Conclusions}

Production waste due its volume is a serious problem in today's economy. It is a big threat to the environment. Waste generated by the production activity is the main subject of reverse logistics due to the scale of occurrence and the possible hazard to the environment. The examined enterprise for environmental purposes not only adopted the minimization of the amount of generated waste, but also the possibility of bringing the processed waste back into the economic cycle as much as possible. Quantitative assumptions for projects reducing the negative impact of generated waste on the environment can only be fulfilled if it is possible to predict the size of waste streams. Various predictive methods are used to manage reverse logistics. They allow for accurate forecasting of waste, which translates into quantitative planning of return flows. The research has shown that forecasts of waste generated using artificial neural networks due to a relatively small forecast error may be the basis for the decision-making process in terms of return flows.

After the data-driven training process, the systems predicted the amount of waste produced on the basis of the previous months. The results showed that the forecasts of the produced waste by neural networks may be the basis for the decision-making process in terms of return flows. Accuracy of forecasts translates into more efficient management of waste streams. Waste amounts in the previous months were inputs to the neural network. We achieved very small prediction errors in the experiments on the real data from the manufacturing company. Future research would involve using other forecasting tools as well as changing the size of the neural network, e.g. by adding more layers. Forecast accuracy translates into better management of waste streams.

\section{References}

[1] Central Statistical Office of Poland, Environment 2016, http://stat.gov.pl/obszarytematyczne/srodowisko-energia/srodowisko/ochrona-srodowiska-2016,1,17.html\#.

[2] Szołtysek J., Twaróg S., Logistyka zwrotna, Teoria i praktyka. Polskie Wydawnictwo Ekonomiczne, Warszawa 2017 (in Polish).

[3] Budică I., Busu O.V., Dumitru A., Purcaru M.-L., Waste management as commitment and duty of Citizens, Polish Journal of Management Studies 2015, 11, 1.

[4] Liberko I., Bednarová L., Hajduová Z., Chovancová J., Ppossibilities to optimize the logistics chain in the manufacturing plant, Polish Journal of Management Studies 2015, 12, 2.

[5] Knosala R., Zastosowania metod sztucznej inteligencji w inżynierii produkcji, Wydawnictwa Naukowo-Techniczne, Warszawa 2002 (in Polish). 
[6] Zieliński J., Inteligentne systemy w zarządzaniu, Teoria i praktyka, Wydawnictwo Naukowe PWN, Warszawa 2000, 142 (in Polish).

[7] Zieliński J., Inteligentne systemy w zarządzaniu. Teoria i praktyka, Wydawnictwo Naukowe PWN, Warszawa 2000, 146 (in Polish).

[8] Bishop C.M., Neural Networks for Pattern Recognition, Oxford University Press, 1995.

[9] Ke Y., Hagiwara M., An English neural network that learns texts, finds hidden knowledge, and answers questions, Journal of Artificial Intelligence and Soft Computing Research 2017, 7, 4, 229-242.

[10] Akdeniz E., Egrioglu E., Bas E., Yolcu U., An arma type Pi-Sigma artificial neural network for nonlinear time series forecasting, Journal of Artificial Intelligence and Soft Computing Research 2018, 8, 1, 121-132.

[11] Scherer R., Multiple Fuzzy Classification Systems, Springer, 2012.

[12] Scherer R., Rutkowski L., Neuro-fuzzy relational systems, International Conference on Fuzzy Systems and Knowledge Discovery, November 18-22, 2002, Singapore, 44-48.

[13] Szajt M., Przestrzeń w badaniach ekonomicznych, Sekcja Wydawnictw Wydziału Zarządzania, Częstochowa 2014 (in Polish). 